\title{
Radioactive and Non-Radioactive Element Analysis of Dorado Gas Discovery of Sri Lanka and Their Influence on Natural Environment
}

\author{
S.S.N. Gamage ${ }^{1 *}$, R.M.T.S.Ratnayake ${ }^{1}$, A.M.A.D.M. Senadhira ${ }^{2}$, D.A. Weerasinghe ${ }^{2}$, \\ V.A. Waduge 3 \\ ${ }^{1}$ Department of Physics, University of Sri Jayewardenepura, Sri Lanka \\ ${ }^{2}$ Petroleum Resources Development Secretariat, Sri Lanka \\ ${ }^{3}$ Atomic Energy Board, Sri Lanka
}

Date Received: 2017-12-10_ Date Accepted: 2018-04-29

\begin{abstract}
Naturally-occurring radionuclides deposited beneath the earth, which are referred to as "NORM" and other toxicnon-radioactive elements transported to the earth surface with the oil and gas production. Hence, knowledge of the prevailing background levels of these elements in the subsurface reservoir formations is valuable to all stakeholders, most notably to regulatory authorities of the country. The drill cuttings obtained within depth range $3025 \mathrm{~m}$ to $3095 \mathrm{~m}$ of reservoir sand section in the deep water exploratory well (CLPL- Dorado $91 \mathrm{H} / 1 \mathrm{z}$ ) drilled in the Mannar Basin offshore Sri Lanka were subjected to high-resolution Gamma-ray spectrometry and X-ray fluorescence (XRF) spectrometry.

As test results revealed activity concentration of ${ }^{40} \mathrm{~K}$ varies from $0.338 \mathrm{~Bq} / \mathrm{g}$ to $0.514 \mathrm{~Bq} / \mathrm{g}$, ${ }^{210} \mathrm{~Pb}$ from $0.007 \mathrm{~Bq} / \mathrm{g}$ to $0.015 \mathrm{~Bq} / \mathrm{g},{ }^{226} \mathrm{Ra}$ from $0.012 \mathrm{~Bq} / \mathrm{g}$ to $0.0145 \mathrm{~Bq} / \mathrm{g}$ while ${ }^{232} \mathrm{Th}$ levels are between $0.030 \mathrm{~Bq} / \mathrm{g}$ to $0.040 \mathrm{~Bq} / \mathrm{g}$. According to the XRF testing levels of significantly hazardous non-radioactive elements are considerably lower, except for the level of the Barium. The Pb level varies between the $48 \mathrm{ppm}$ to $22 \mathrm{ppm}$. The Thorium level varies between $9.6 \mathrm{ppm}$ to $10.1 \mathrm{ppm}$. Manganese has a range of 5,173ppm to $653 \mathrm{ppm}$. The barium levels are between $118,666 \mathrm{ppm}$ to $24,400 \mathrm{ppm}$. NORM concentration of the tested section were on the lower side when results matched with the IAEA published data on NORM concentration in oil, gas and there byproducts and therefore there will be low level of NORM contaminations when the Dorado gas discovery proceeds to the production stage. Further there is no harmful public exposure from NORM by disposing these drill cuttings to environment or storing at any site location. But the disposal of the drilling mud and handling of the drilling mud should be conducted with cautious since extremely high Ba levels can potentially cause health problems.
\end{abstract}

Keywords: NORM, drill-cuttings, oil, gas, Sri Lanka, XRF

\section{Introduction}

\subsection{Background}

Sri Lankan upstream petroleum industry is still in the early phases of exploration in which wells are drilled to discover and assess hydrocarbon and to derive fundamental strategies for future development stages. It had been started in 1960's and during 1972-1975 first three exploration wells were drilled Pesalai-1, Pesalai-2 and Pesalai-3 in the Cauvery Basin of Sri Lanka. Later, Palk Bay-1 and Delft- in 1976 and Pedro-1 and Pearl -1 in 1981were drilled but there have not been any significant hydrocarbon discoveries except small discovery in Pesalai-1.

${ }^{*}$ Correspondence: shanthagamage@sci.sjp.ac.lk

ISSN 2235-9370 Print/ISSN 2235-9362 Online @ C University of Sri Jayewardenepura 
Then in 2001, 2005, 2009 and 2012 seismic surveys has been carried out to acquire vital data. (PRDS-Sri Lanka, 2017) Most recently starting from 2011 four new wells Dorado, Dorado-north, Barracuda and Wallago have been drilled and discovered natural gas from Dorado and Barracuda wells (Ratnayake et al., 2017).

This study was primarily focused on obtaining the NORM concentration levels of the drill cuttings from the gas reservoir sand section of the Dorado gas discovery off-shore Mannar Basin, compare those obtained levels with the global NORM levels, and correlate the results with well $\log$ data. Moreover, XRF testing results was conducted to determine non-radioactive hazardous elements.

The subsurface formations which are rich in hydrocarbons are also comprise naturallyoccurring radionuclides; Uranium, Thorium, Potassium, Radium and Lead which are referred to as "NORM" (Paranhouz, 2005) plus non-radioactive materials which are toxic to natural environment. Industrial processes involved in oil and gas production such as treating and refining activities direct all these elements which are trapped inside rock layers of the earth to flow to the surface and contaminate natural environment (Gray, 1993, Godoy, 2003), as such radionuclides along with the other minerals which are dissolved in the salty water, precipitate out and forming various wastes at the surface during the different stages of the oil and gas production.

Some of these NORM contaminated waste associate with the production of the petroleum industry are, hard mineral scales formed inside the pipes, sludge disposed after treating water and hydrocarbons, contaminated equipment and components and produced water. IAEA safety report (2003), IAEA training course report (2010). Since the petroleum production processes are collecting and concentrating these NORM associated waste and other toxic materials, there is a prospective of exposing them to the natural environment. Therefore identification of background level of NORM and non-radioactive hazards materials in the subsurface hydrocarbon bearing formations will be beneficial in predicting contamination levels during the oil and gas production.

The Department of Physics, University of Sri Jayewardenepura collaboratively conducted this study with the Petroleum Resources Development Secretariat and Atomic Energy Board of Sri Lanka and this was the first study which has been conducted regarding the NORM background levels of discovered reservoir sand sections in the drilled exploratory wells in the Mannar Basin offshore Sri Lanka.

\subsection{Location of the study}

The Mannar basin is located at approximately $60^{\circ}-90^{\circ}$ North latitude by $78^{\circ}-80^{\circ}$ East longitude, and bounded from south west to north west Sri Lanka, south east of India and south of the Cauvery basin. In terms of size, the SL side of the Mannar basin approaches in an area of approximately 42,000 $\mathrm{km}^{2}$ with a sediment accumulation of possibly up to $10 \mathrm{kms}$ in the deeper water areas of the basin. The Dorado well where drill cuttings were obtained is located in M2 block of Mannar Basin as shown in Figure 1 (PRDS-Sri Lanka, 2013). CLPL-Dorado-91H/1z (Dorado), well was drilled in a water depth of $1354 \mathrm{~m}$, which penetrated a hydrocarbon rich sandstone between the depths of 3,044-3,069 m, measured depth (MD). Total depth of the well was 3,288 m, MD. It is the first exploration well to discover hydrocarbons in the Gulf of Mannar. 


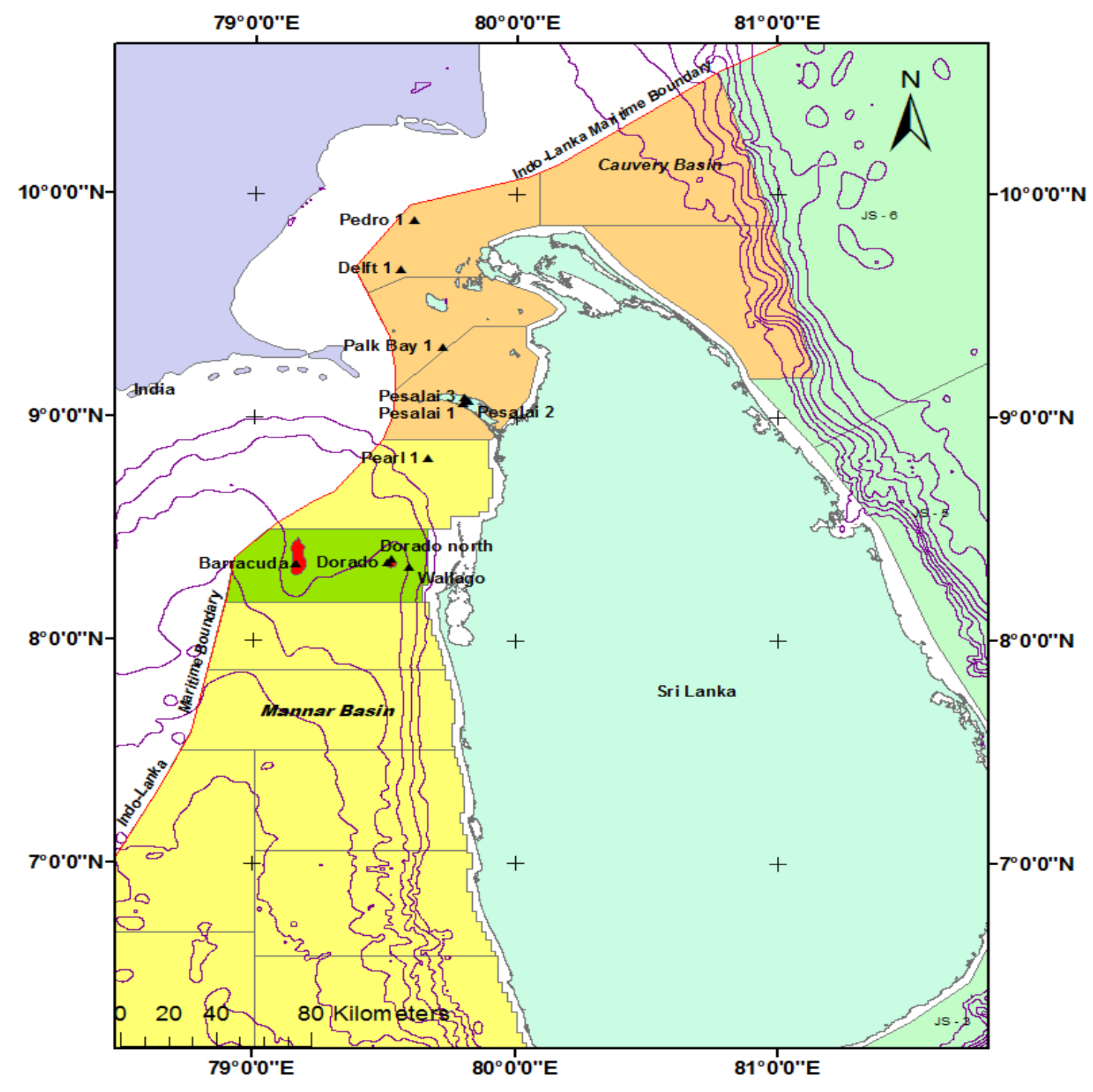

Figure 1. Location of the Gas discoveries and other exploration wells (Ratnayake et al., (2017).

\section{Methodology}

\subsection{Sample selection \& preparation}

Suitable depth range was decided for the samples selection using seismic and well log data. Then 15 samples each weighing about $250 \mathrm{~g}$ were taken from 3,025 $\mathrm{m}$ to 3,095 $\mathrm{m}$ depth range with five meter intervals. Then the drill cutting samples were air-dried. After that samples were oven dried at $100^{\circ} \mathrm{C}$ temperature for 10 hours to get rid of all the moisture and packed into sealed polyethylene bags.

\subsection{Gamma Ray Spectroscopy}

The dried drill cutting samples were grinded and were sieved through a sieve of $2 \mathrm{~mm}$ size. Then, fine powdered samples were packed and sealed in an airtight G1 geometry container for gamma spectrometry testing and labeled according to their respective depths. Then they were stored for 21 days before its testing to achieve the secular equilibrium between elements. 
This test was carried out at the Atomic Energy Board of Sri Lanka, using a high-resolution gamma spectrometer. The gamma spectrometry system was equipped with a coaxial n-type high purity germanium (HPGe) detector connected through amplifiers and multi-channel analyzer driven by a computer based operating system. The detector had a coaxial closed facing geometry with the following specifications. Detector mode GX3020 with a resolution of full width at half maximum (FWHIM) at $122 \mathrm{Kev}$ of Co-57. The detector was shielded by a cylindrical lead shield, which had average thickness of $10 \mathrm{~cm}$ to reduce the background radiation. Genie 2000 software package was used for data acquisition. HPGe gamma spectrometry system was calibrated using the point sources of $137 \mathrm{Cs}, 60 \mathrm{Co}$ and $241 \mathrm{Am}$ and calibration was verified using the IAEA reference materials. The efficiency calibration was done by Geometric Composure method (Lab SOCS, Canberra) and the test method was validated by analyzing standard reference material, IAEA-134 and IAEA-414 (Ratnayake et al., 2017).

\subsection{Total activity concentration}

Total Activity Concentration for Uranium, Thorium series and for potassium was calculated using the following Equation 1 (Omar et al 2008)

$\mathrm{TAC}={ }^{40} \mathrm{~K}+6 \mathrm{x}{ }^{226} \mathrm{Ra}+3 \mathrm{x}^{210} \mathrm{~Pb}+{ }^{232} \mathrm{Th}$

\subsection{Correlation with well logs}

Test results obtained from the testing were statistically analyzed with the well log data (Gamma ray $\log$ ) to validate the test results. Minitab software was used for the analysis. Since the well logs were in different units (GAPI) the two data sets were standardized. Then $2 \mathrm{k}$ factorial design test was applied and $\mathrm{p}$ value was obtained.

\subsection{XRF testing}

Five samples were selected to represent the total depth covering the reservoir sand section. From each samples $2 \mathrm{~g}$ quantity was separated at first.Then using non contamination hand grinder the samples were grinded. Then it was sieved by a sieve size of $63 \mathrm{~mm}$ and obtained $0.5 \mathrm{~g}$. After that pressed powder method was used to prepare pellets. In the process of making pellets, $0.05 \mathrm{~g}$ of cellulose was added to $0.15 \mathrm{~g}$ of drill cutting powders. Cellulose was used as a bind in making of pellets in order to pellets unbroken (IAEA 1983), (Demir et al., 2006).

\section{Results and discussion}

\subsection{Gamma ray spectroscopy results}

When results of the tested samples between depth the interval considered ${ }^{40} \mathrm{~K}$ has the highest activity concentration among the elements which has highest level of $0.514 \mathrm{~Bq} / \mathrm{g}$ and a minimum value of $0.338 \mathrm{~Bq} / \mathrm{g}$. The activity concentration levels of ${ }^{210} \mathrm{~Pb}$ varied from $0.007 \mathrm{~Bq} / \mathrm{g}$ to $0.015 \mathrm{~Bq} / \mathrm{g}$, whereas ${ }^{232} \mathrm{Th}$ varied from $0.030 \mathrm{~Bq} / \mathrm{g}$ to $0.040 \mathrm{~Bq} / \mathrm{g}$ while ${ }^{226} \mathrm{Ra}$ showed an activity concentration range of $0.0145 \mathrm{~Bq} / \mathrm{g}$ to $0.012 \mathrm{~Bq} / \mathrm{g}$. According to calculated values of total activity concentration with depth, the total activity concentration has a maximum value of $0.64 \mathrm{~Bq} / \mathrm{g}$ and minimum value of 0.51 $\mathrm{Bq} / \mathrm{g}$ within the tested depth interval and moderately consistence throughout the 3020-3095 depth interval 
Table 1: Table of Activity concentration level with error for tested depths.

\begin{tabular}{llllll}
\hline $\begin{array}{l}\text { Depth } \\
\text { interval }(\mathrm{m})\end{array}$ & $\begin{array}{l}\text { Average } \\
\text { depth }\end{array}$ & $\mathrm{K}-40(\mathrm{~Bq} / \mathrm{g})$ & $\mathrm{Pb}-210(\mathrm{~Bq} / \mathrm{g})$ & $\begin{array}{c}\mathrm{Ra}-226 \\
(\mathrm{~Bq} / \mathrm{g})\end{array}$ & $\begin{array}{c}\text { Th-232 } \\
(\mathrm{Bq} / \mathrm{g})\end{array}$ \\
\hline $3020-3025$ & 3022.5 & $0.388 \pm 0.016$ & $0.007 \pm 0.001$ & $0.012 \pm 0.001$ & $0.030 \pm 0.002$ \\
$3025-3030$ & 3027.5 & $0.410 \pm 0.028$ & $0.011 \pm 0.002$ & $0.013 \pm 0.001$ & $0.031 \pm 0.003$ \\
$3030-3035$ & 3032.5 & $0.430 \pm 0.030$ & $0.009 \pm 0.002$ & $0.014 \pm 0.001$ & $0.032 \pm 0.003$ \\
$3035-3040$ & 3037.5 & $0.401 \pm 0.028$ & $0.015 \pm 0.002$ & $0.013 \pm 0.001$ & $0.031 \pm 0.003$ \\
$3040-3045$ & 3042.5 & $0.421 \pm 0.018$ & $0.008 \pm 0.002$ & $0.014 \pm 0.001$ & $0.035 \pm 0.003$ \\
$3045-3050$ & 3047.5 & $0.413 \pm 0.028$ & $0.009 \pm 0.002$ & $0.014 \pm 0.002$ & $0.035 \pm 0.003$ \\
$3050-3055$ & 3052.5 & $0.413 \pm 0.027$ & $0.007 \pm 0.002$ & $0.013 \pm 0.001$ & $0.036 \pm 0.004$ \\
$3055-3060$ & 3057.5 & $0.420 \pm 0.028$ & $0.0004 \pm 0.0001$ & $0.014 \pm 0.001$ & $0.035 \pm 0.004$ \\
$3060-3065$ & 3062.5 & $0.422 \pm 0.028$ & $0.009 \pm 0.002$ & $0.014 \pm 0.001$ & $0.037 \pm 0.004$ \\
$3065-3070$ & 3067.5 & $0.406 \pm 0.029$ & $0.009 \pm 0.002$ & $0.014 \pm 0.001$ & $0.036 \pm 0.004$ \\
$3070-3075$ & 3072.5 & $0.422 \pm 0.029$ & $0.011 \pm 0.002$ & $0.014 \pm 0.001$ & $0.038 \pm 0.004$ \\
$3075-3080$ & 3077.5 & $0.435 \pm 0.030$ & $0.011 \pm 0.002$ & $0.015 \pm 0.001$ & $0.040 \pm 0.004$ \\
$3080-3085$ & 3082.5 & $0.426 \pm 0.030$ & $0.012 \pm 0.002$ & $0.014 \pm 0.001$ & $0.035 \pm 0.002$ \\
$3085-3090$ & 3087.5 & $0.514 \pm 0.036$ & $0.009 \pm 0.002$ & $0.012 \pm 0.001$ & $0.031 \pm 0.003$ \\
$3090-3095$ & 3092.5 & $0.419 \pm 0.029$ & $0.008 \pm 0.002$ & $0.012 \pm 0.001$ & $0.035 \pm 0.004$ \\
\hline
\end{tabular}

Table 2 consist of NORM concentration levels in oil, gas and their byproducts from IAEA safety report (2003), hence when compared that levels with NORM levels of reservoir section it implies that the activity concentration result levels in a low range. Moreover, the whole amount of the NORM in the reservoir are not mobilizing to the surface therefore the levels in the productions should be in much lower levels. According to the output of the $2 \mathrm{k}$ factorial design which was applied to check whether there is a significant difference test results and gamma ray log, the obtained p-value is 0.941.This $\mathrm{p}$ value is greater than the significance level of $5 \%$ which means there are no evidence for us to reject the null hypothesis which states that test results are equal to the gamma ray log data. Therefore we could conclude that there is no significance difference between the test results and gamma ray log. Hence this statistical analysis validate the gamma ray spectrometry test results to a certain extent, but the number of samples tested was not sufficient to conduct advanced analysis between results and gamma ray log hence the accuracy of the analysis will not be in a higher percentage.

Table 2: Concentration levels of NORM in oil, gas and by products IAEA safety report (2003).

\begin{tabular}{cccccc}
\hline $\begin{array}{c}\text { Radio- } \\
\text { nuclide }\end{array}$ & $\begin{array}{c}\text { Crude oil } \\
\mathrm{Bq} / \mathrm{g}\end{array}$ & $\begin{array}{c}\text { Natural gas } \\
\mathrm{Bq} / \mathrm{m}\end{array}$ & $\begin{array}{c}\text { Produced water } \\
\mathrm{Bq} / \mathrm{L}\end{array}$ & $\begin{array}{c}\text { Hard scale } \\
\mathrm{Bq} / \mathrm{g}\end{array}$ & $\begin{array}{c}\text { Sludge } \\
\mathrm{Bq} / \mathrm{g}\end{array}$ \\
\hline${ }^{238} \mathrm{U}$ & $<0.01$ & - & $0.0003-0.1$ & $0.001-0.5$ & $0.005-0.01$ \\
${ }^{226} \mathrm{Ra}$ & $0.000-0.04$ & - & $0.002-1200$ & $0.1-15000$ & $0.05-800$ \\
${ }^{210} \mathrm{Po}$ & $0-0.01$ & $0.002-0.08$ & - & $0.02-1.5$ & $0.004-160$ \\
${ }^{210} \mathrm{~Pb}$ & - & $0.005-0.02$ & $0.05-190$ & $0.02-75$ & $0.1-1300$ \\
${ }^{222} \mathrm{Rn}$ & - & $5-200000$ & - & - & - \\
${ }^{232} \mathrm{Th}$ & $0.000-03-0.002$ & - & $0.0003-0.001$ & $0.001-0.002$ & $0.002-0.01$ \\
${ }^{228} \mathrm{Ra}$ & - & - & $0.3-180$ & $0.0-2800$ & $0.5-50$ \\
${ }^{224} \mathrm{Ra}$ & - & - & $0.5-40$ & - & - \\
\hline
\end{tabular}


According to the XRF test results levels of significantly hazardous elements are considerably in the lower range, except the level of the Barium (Ba). Pb varies between the $48 \mathrm{ppm}$ to $22.2 \mathrm{ppm}$. The Thorium level varies between $9.6 \mathrm{ppm}$ to $10.1 \mathrm{ppm}$. Manganese has a range of 5,173.333 ppm to $653.3333 \mathrm{ppm}$. The barium levels are between $118,666.7 \mathrm{ppm}$ to $24,400 \mathrm{ppm}$.

Table 3: Element concentrations in ppm according to the depth.

\begin{tabular}{lccccc}
\hline Element & $\begin{array}{c}3,090-3,095 \\
(\mathrm{~m})\end{array}$ & $\begin{array}{c}3,075-3,080 \\
(\mathrm{~m})\end{array}$ & $\begin{array}{c}3,060-3,065 \\
(\mathrm{~m})\end{array}$ & $\begin{array}{c}3,045-3,050 \\
(\mathrm{~m})\end{array}$ & $\begin{array}{c}3,030-3,035 \\
(\mathrm{~m})\end{array}$ \\
\hline $\mathrm{K}$ & $19,466.670$ & $20,400.000$ & $17,600.000$ & $15,200.000$ & $13,600.000$ \\
$\mathrm{Ca}$ & $190,666.700$ & $165,333.300$ & $148,000.000$ & $137,333.300$ & $137,333.300$ \\
$\mathrm{Ti}$ & $5,773.333$ & $3,186.667$ & $3,000.000$ & 0.000 & 0.000 \\
$\mathrm{BA}$ & $24,400.000$ & $106,933.300$ & $98,133.330$ & $112,666.700$ & $118,666.700$ \\
$\mathrm{~V}$ & 570.667 & $1,973.333$ & $1,866.667$ & $2,826.667$ & $3,413.333$ \\
$\mathrm{CR}$ & 0.000 & 0.000 & 0.000 & 0.000 & 241.333 \\
$\mathrm{CE}$ & 0.000 & 0.000 & $2,693.333$ & 0.000 & 0.000 \\
$\mathrm{MN}$ & 653.333 & 654.667 & $5,173.333$ & $4,386.667$ & $4,093.333$ \\
$\mathrm{FE}$ & $51,866.670$ & $53,600.000$ & $38,666.670$ & $31,600.000$ & $31,466.670$ \\
$\mathrm{CO}$ & 181.333 & 115.733 & 78.000 & 96.933 & 0.000 \\
$\mathrm{NI}$ & 156.000 & 82.667 & 102.533 & 64.533 & 54.533 \\
$\mathrm{CU}$ & 50.533 & 73.467 & 326.667 & 314.667 & 254.667 \\
$\mathrm{ZN}$ & 77.467 & 165.333 & 961.333 & 849.333 & 801.333 \\
$\mathrm{GA}$ & 32.267 & 24.800 & 116.667 & 105.600 & 95.333 \\
$\mathrm{AS}$ & 41.067 & 0.000 & 0.000 & 0.000 & 0.000 \\
$\mathrm{~PB}$ & 22.267 & 39.467 & 48.000 & 41.333 & 46.000 \\
$\mathrm{BR}$ & 13.600 & 12.933 & 4.640 & 5.187 & 6.493 \\
$\mathrm{RB}$ & 68.000 & 67.733 & 43.067 & 36.267 & 35.867 \\
$\mathrm{SR}$ & 540.000 & 546.667 & 458.667 & 418.667 & 458.667 \\
TH & 9.653 & 10.133 & 0.000 & 0.000 & 0.000 \\
Y & 11.973 & 22.000 & 9.733 & 8.000 & 8.493 \\
\hline
\end{tabular}

As clearly visible in Figure $2 \mathrm{Ca}, \mathrm{Ba}, \mathrm{Fe}$ has considerable levels of element concentrations in tested samples. Only the Barium levels are considerably higher than expected international levels. This can be due to the effect of drilling mud mixed with the drill cuttings as the samples were only dried without washing. When preparing drilling mud, $\mathrm{BaSO}_{4}$ is added to the fluid mixture to increase the density hence this indicates that drilling mud contains very high amount of $\mathrm{Ba}$. 


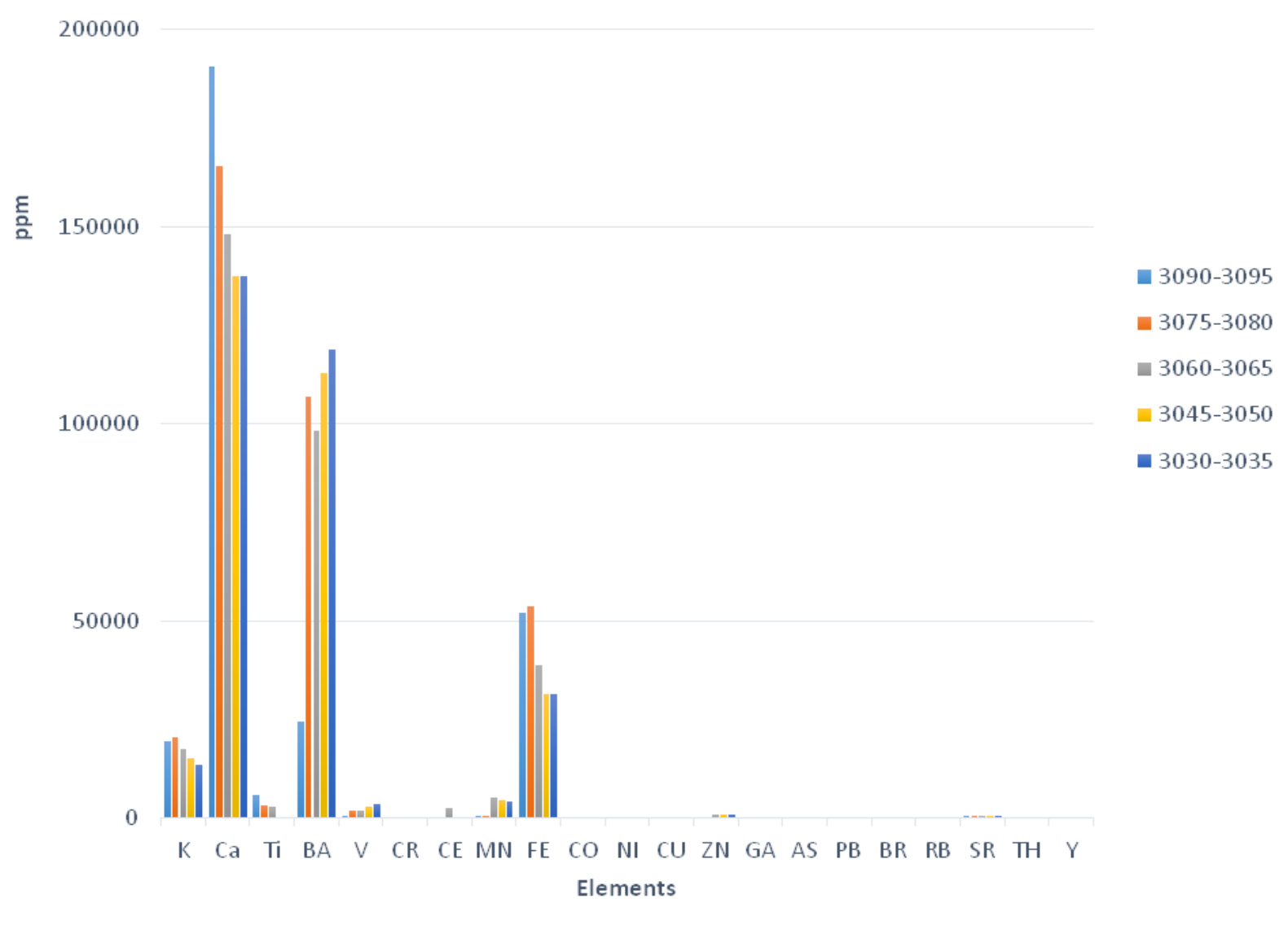

Figure 2: Element concentrations in ppm with depth.

\section{Conclusion}

When the Gamma-ray spectrometry taken in to the consideration, the activity concentrations levels of ${ }^{40} \mathrm{~K}$ are most prominent and considerably higher than the other NORM elements. ${ }^{210} \mathrm{~Pb},{ }^{226} \mathrm{Ra}$ and ${ }^{232}$ Th levels do not vary considerably throughout the depth range tested. Further, the accuracy of the test results of Gamma ray spectrometry were confirmed by the final result of the statistical comparison with gamma ray log data, as $\mathrm{P}$ value is higher than $5 \%$ it indicates these is no significant difference between gamma ray log and experimental radiation levels. Since the tested sample is small.

The results indicates the NORM levels of the Dorado gas reservoir sand section is low reasonably to the sedimentary rocks found around the world, hence the mobilizing amount of NORM levels to the earth surface have to be lower than the levels of the reservoir which are significantly in the lower side when compared to the IAEA levels, Hence if appropriate production and waste disposal procedures can be implemented such as treatment of produced water before disposal or reusing in well operations, procedure for disposal of sludge and solid waste with minimum environmental impact, health and safety regulations for workers in the oil and gas fields according to the American Petroleum Institute and International Atomic Energy Agency standards (Environmental Protection for Onshore Oil and Gas Production Operations and Leases, 2009), (Overview of exploration and production waste volumes and waste management practices in the united states, 2000), (Guidelines for Commercial Exploration and Production Waste Management Facilities,2001) and IAEA (2010), (2003) then the amount of contaminations from NORM can further be minimized. (Ratnayake et al., 2017).

Moreover, when considering the XRF results, apart from NORMs the attention should be given to the other non-radioactive hazardous element concentrations as well since the long term accumulations can pose a threat in the future. As clearly visible, only $\mathrm{Ca}, \mathrm{Ba}, \mathrm{Fe}$ has considerable levels of element concentrations in tested samples and apart from that the Barium levels are 
considerably higher than expected international levels. This can be due to the effect of drilling mud mixed with the drill cuttings as the samples were only dried without washing. When preparing drilling mud, $\mathrm{BaSO}_{4}$ is added to the fluid mixture to increase the density. Therefore the disposal of the drilling mud and handling of the drilling mud should be conducted in a careful manner since extremely high Ba levels can potentially cause health problems. Accepted barium levels are varied between $15 \mathrm{ppm}$ to 3,500 ppm (Tox Guide TM for Barium, 2007).

The acceptable levels can be varied around the world according to the geographical conditions and environmental sensitivity. Therefore conducting the both of these testing for drill cutting samples obtained from the other remaining wells to get a generalized value range for sedimentary rocks in the Mannar basin, Sri Lanka would be vital for the future proceedings.

\section{Acknowledgement}

Special gratitude to petroleum resources development secretariat for providing required data and financial funds to conduct the research successfully.

\section{References}

Canadian Association of Petroleum Producers (2000) Naturally Occurring Radioactive Material (NORM) guide. Canada, pp.9.

Demir, F., Budak, G., Baydaş, E. and Şahin, Y. (2006). Standard deviations of the error effects in preparing pellet samples for WDXRF spectroscopy. Nuclear Instruments and Methods in Physics Research Section B: Beam Interactions with Materials and Atoms, 243(2), pp.423-428.

Environmental Protection for Onshore Oil and Gas Production Operations and Leases (2009) Available at: http://www.api.org/ /media/files/policy/exploration/api_rp_51r.ashx.

Godoy, J.M. and Petinatti da Cruz, R. (2003) '226Ra and 228Ra in scale and sludge samples and their correlation with the chemical composition', Journal of Environmental Radioactivity, 70(3), pp. 199-206.

Gray, P.R. (1993) 'NORM contamination in the petroleum industry', Journal of Petroleum Technology, 45(01), pp. 12-16.

Guidelines for the management of Naturally Occurring Radioactive Material (NORM) in the oil \& gas industry Report No: 412 (2008). Available at:

ftp://ftp.consrv.ca.gov/pub/oil/SB4DEIR/docs/HAZ_IAOGP_2008.pdf.

Guidelines for Commercial Exploration and Production Waste Management Facilities (2001) Available at: http://www.api.org/ /media/Files/EHS/

Environmental_Performance/E_P_Waste_Guidelines.pdf.

IAEA (2003) Radiation Protection and the Management of Radioactive Waste in the Oil and Gas Industry. Safety report series.

IAEA (2010) Radiation protection and the management of radioactive waste in the oil and gas industry, Training course Series No.40. Available at: http://www-pub.iaea.org/MTCD/publications/PDF/TCS-40_web.pdf

IAEA (1983) Sample preparation techniques in trace element analysis by X-ray emission spectroscopy, Vienna: pp.112-113.Available at:

http://www.iaea.org/inis/collection/NCLCollectionStore/_Public/15/022/15022526.pdf [Accessed 23 Apr. 2018].

Omar, M., Hamzah, M.S. and Wood, A.K. (2008) 'Radioactive disequilibrium and total activity concentration of NORM waste', J NUCL. \& Rel. TECH, Volume 5(2), pp. 47-56.

Overview of Exploration and Production Waste Volumes and WasteManagement Practices in the United States (2000) Available at: http:// www.api.org/ /media/files/ehs/environmental_performance/icf-wastesurvey-of-eandp-wastes2000.pdf?la=en.

Prds-srilanka.com. (2017). PRDS Sri Lanka - Origins. Available at: http://www.prdssrilanka.com/exploration/origins.faces

PRDS (2013) PRDS Sri Lanka - regional geology. Available at: http://www.prdssrilanka.com/exploration/mannarBasin.faces;jsessionid=D7E49C8B71958661FA9A0E253AC A7\%20D1C.jvm1. 
Ratnayake, R. M. T. S., Gamage, S. S. N., Senadhira, A. M. A. D. M., Weerasinghe, D. A. and Waduge, V. A.(2017). NORM analysis of the reservoir sand section in the Dorado natural gas discovery, Mannar basin offshore Sri Lanka. Journal of the Geological Society of India, 89(6), pp.683-688.

ToxGuide TM for Barium. (2007). [ebook] Atlanta, GA: Agency for Toxic Substances and Disease Registry. Available at: https://www.atsdr.cdc.gov/toxguides/toxguide-24.pdf [Accessed 9 Sep. 2017]. 